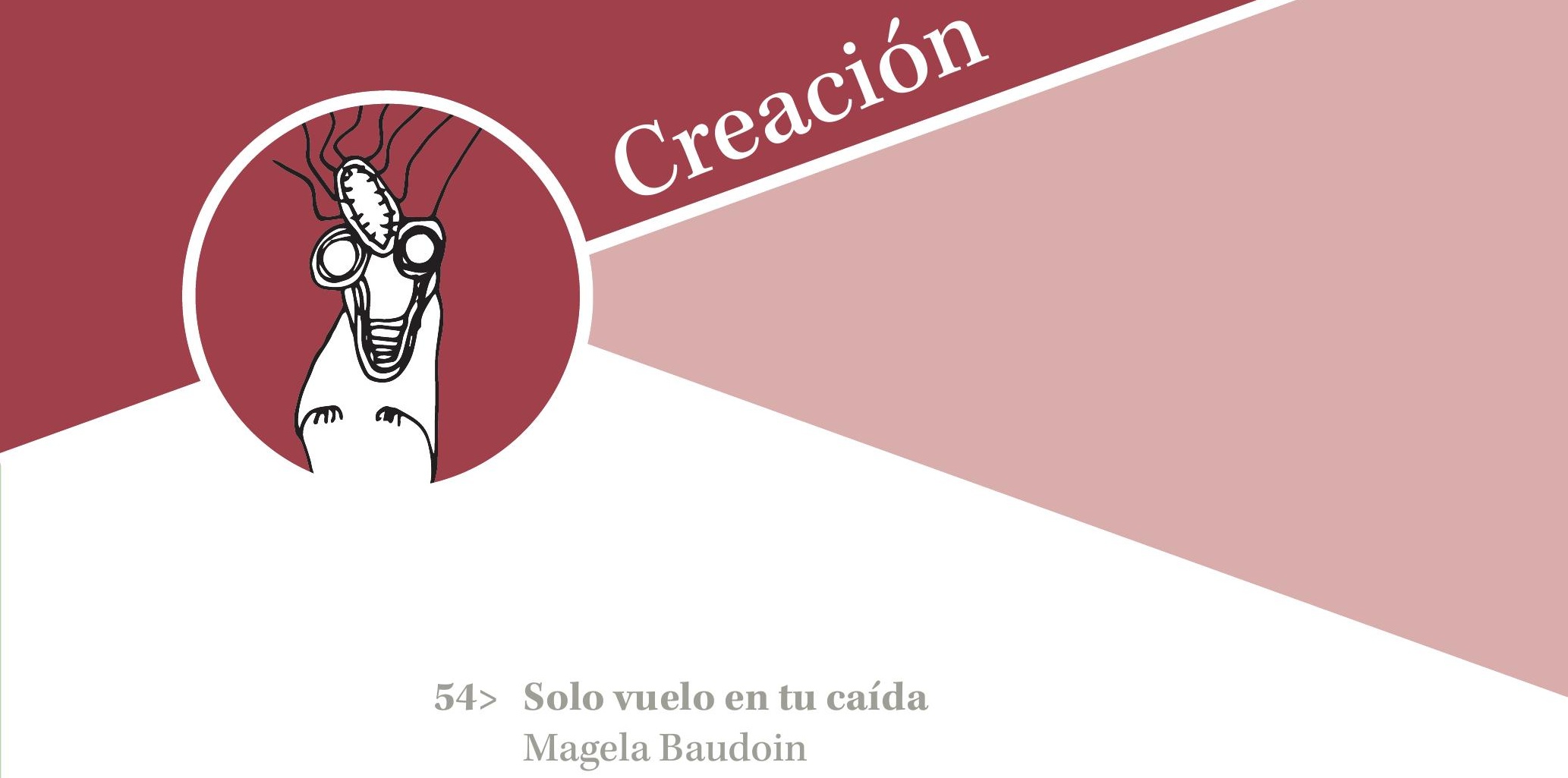




\section{Solo vuelo en tu caída}

MAgela BAUdoin

La escritora y periodista boliviana Magela Baudoin obtuvo el Premio Hispanoamericano de Cuento Gabriel García Márquez por su libro La composición de la sal (2014). Su último libro fue finalista del VI Premio Ribera del Duero-Páginas de Espuma (2020), en España, con el título Solo vuelo en tu caída, que será publicado este año, y del que ahora se adelanta el cuento homónimo.

A mi hermana Natalia.

Prolija memoria, permite, siquiera, que por un instante sosieguen mis penas.

Sor Juana Inés de la Cruz

\section{EL TRAJE}

Adriano no podía tardar más de treinta minutos. Tenía el tiempo justo para sacar el dinero de la mesa de noche de mamá y elegir la ropa con que Nico entraría al ataúd; también debía elegir la muda que Filis necesitaba para cambiarse el uniforme sucio. Tenía que apurarse pues papá y mamá lo estaban esperando para pagar los servicios funerarios y Filis estaba llena de sangre, todavía en la clínica, con Neera. No sabía qué era peor: si comprar el ataúd y vestir a Nico o consolar a Filis. El suyo era el trabajo más fácil, se decía, y quería con todas sus fuerzas hacerlo bien y rápido, tratando de mantener a raya su voz y su corazón vacilantes. No sentir, solo hacer. Levantar 50 kilos en discos de peso y empujar para no quedar triturado por la carga de los acontecimientos. Cerrar los ojos y solo empujar. 
Mas su fuerza lo estaba traicionando. Los tobillos le temblaban de tal modo que no había podido presionar los pedales y echar a andar el auto. Adriano golpeó el volante. Por suerte nadie, excepto su cuñado, lo vio. Sergio le quitó la llave y condujo callado. Adriano se lo agradeció. Sabía cómo encontrar valor en la ira. Se bajó del auto resuelto a salir del departamento tan pronto como entraran. Abrió la puerta principal del edificio y se fijó en que las manchas de sangre del atrio habían sido limpiadas.

El departamento había quedado a oscuras. Encendió la luz del pasillo y los detuvo una corriente de aire helado que provenía de una ventana abierta, en la habitación que compartía con Nico. Compartir habitación nunca le había molestado a Adriano, ni antes de irse de intercambio ni al regresar. En realidad, Nico le había hecho más suave el retorno porque no lo examinaba, no tenía desilusiones sobre el futuro y, además, por alguna razón que Adriano no entendía, lo admiraba. Quería ser como él, a pesar de que había descartado la beca en Estados Unidos para quedarse a estudiar en Bolivia. ¿Quién quiere estudiar en Bolivia? Adriano tenía un desapego por el porvenir que le ponía a mamá los pelos de punta y a todos los demás podía parecerles, en algún punto, dejadez, distracción, lentitud. A Nico aquel gusto de Adriano por lo insignificante le parecía lo mejor. Mi hermano es el más de la puta, decía Nico. Juntos se habían vuelto adictos a las artes marciales, a la ciencia ficción y, ahora último, a las revistas de manga.

Se paró en el umbral de la puerta abierta y observó las dos camas deshechas. Las almohadas yacían en el piso y sobre el cobertor. Nico y él las usaban como sacos de boxeo. Se aproximó a la ventana abierta. No había un solo vidrio sobre la cama como él había supuesto. El del ventanal estaba entero. Sacó el pecho hacia afuera del edificio, experimentó por unos segundos el magnetismo del vértigo y compuso una explicación de inmediato, un manto que amortiguara la caída y que pudiera protegerlos. Mamá no soportaría las dudas. Adriano le había dicho muchas veces a Nico que el que pegaba primero, pegaba dos veces, que llevaba la ley de la ventaja. No iba a permitir que se instalara otra verdad que la suya: el juego. Eso es lo

\section{6}

Adriano le había dicho muchas veces a Nico que el que pegaba primero, pegaba dos veces, que llevaba la ley de la ventaja. No iba a permitir que se instalara otra verdad que la suya: el juego.

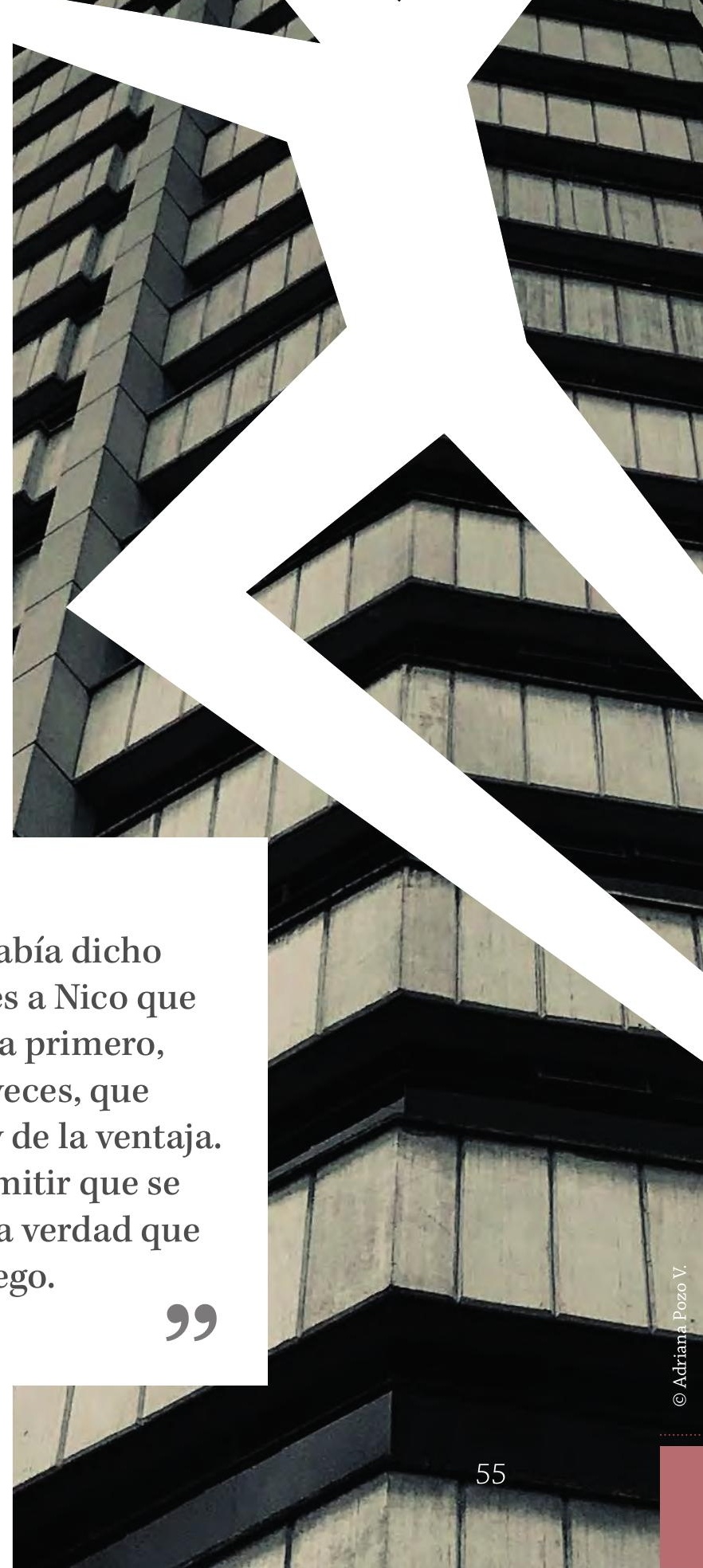


que le diría a la Policía, a sus padres y hermanos, a los amigos. Nico había estado saltando de una cama a la otra, lanzando las patadas que él mismo le había enseñado. Sergio presionaba: Ya vámonos, hermano. Pero Adriano iba y volvía de una cama a la otra, midiendo la extensión de un salto, la abertura de una patada, el ángulo del desplazamiento. Nico había caído de espaldas, boca arriba, no de bruces. Por eso tenía el rostro intacto, los ojos asombrados y los labios entreabiertos. Vamos, Adriano, la ropa... Sí, su hermano había perdido el equilibrio jugando. Había caído de espaldas por la ventana abierta. Esa era la historia. Adriano revolvió el clóset y no encontró nada adecuado. ¿Hay ropa «adecuada» para un entierro? ¿Debería elegir algo nuevo y elegante o más bien lo que más le gustaría usar a Nico?

De todas maneras, el guardarropa de su hermano era más bien escueto: tres pantalones, un par de chompas viejas, ninguna camisa de vestir, nada a la moda. Filis siempre se quejaba de que no «tenían» ropa. A todos los demás, lo de la ropa les parecía superficial, una exageración, un efecto idiota del colegio caro que apenas se podía pagar. Pobrecita la niña que no tiene qué ponerse, se había burlado Adriano muchas veces. Ponía énfasis en el «pobrecita», riéndose. Lo más pasable que tenía Nico era el uniforme de karate blanco, con el cinto verde. ¿Qué dices?, preguntó y Sergio asintió. ¿Medias? ¿Calzoncillos? Sergio volvió a asentir. Adriano había llevado a Nico al karate para que aprendiera a defenderse, pero él nunca estuvo muy bien dotado para la pelea. No le gustaba golpear sino elevarse en el aire, hacer figuras, volteos, patadas, y caer de pie como un felino. Adriano, vamos de una vez, hombre. Sí, sí.

Faltaba Filis. Había sido Neera, la mayor, quien le pidió una muda para Filis, luego de lavarle la cara y las manos manchadas de sangre en el baño de la clínica. Su hermana todavía llevaba la polera del colegio, una polera que había que tirar a la basura, había dicho Neera, y un blue jean gastado que seguramente también habría que botar. El óxido, el olor, el sabor de la sangre eran fulminantes para Adriano. Alguna vez había sido donante y en cada pinchazo, al ver entrar el chorro delgado y oscuro en el tubo de ensayo, le venía la náusea y el desmayo instantáneo. Filis se burlaba de él: ¡En tu tamañote!, le decía. Y, a pesar de eso, aquel día sí había podido. Había alzado a Filis, le había besado las manos con la sangre seca. Ella no hablaba y él tampoco. Solo Neera podía ponerlos en marcha. Ve, ve rápido que no puede estar más así, mira cómo ha dejado la silla manchada. Neera se parecía a mamá, solo que su debilidad era Filis, la de su madre era... Mamá había entrado al quirófano a una operación inútil, que todos sabían que no resultaría, pero que igual intentaron en busca de un milagro. Adriano, jvamos! Filis tampoco tenía demasiadas opciones, pero sí una camisa y un pantalón oscuros. Medias, zapatos. Sí, una chamarra para
El óxido, el olor, el sabor de la sangre eran fulminantes para Adriano. Alguna vez había sido donante y en cada pinchazo, al ver entrar el chorro delgado y oscuro en el tubo de ensayo, le venía la náusea y el desmayo instantáneo. 
el frío. Salieron rápido, cerraron la puerta del departamento, sin echar llave, y cuando el ascensor se abrió en la planta baja, Adriano dijo: ¡Mierda, el dinero!

Era más de la medianoche cuando llegaron a la clínica, luego de pasar por la funeraria. Todo parecía distinto: más lento y neutral. No quedaba nadie en los pasillos ni en las sillas de espera, y las enfermeras pasaban casi levitando. Neera los esperaba en la antesala del consultorio donde reposaba Filis sobre una camilla. Mamá estaba en la funeraria con papá, vistiendo a Nico. Papá había tosido para no llorar al ver el traje de karate.

¡Por fin!, dijo Neera al verlos aparecer y, antes de que pidiera nada, le fueron pasando lo que habían traído para Filis: pantalón, camisa, medias, zapatos... ¿Y la ropa interior?, preguntó Neera. No habían pensado en eso, a pesar de que habían sacado calzoncillos para Nico, ni se les había cruzado por la mente. Ella les sonrió con piedad. Sergio vio que le temblaban los labios. Es horrible, dijo Neera, y Sergio vio a Filis consumida por la penumbra. No pudo evitar pensar en la niña que lo recibía cuando recién iba a visitar a Neera. Hola, mocosa, le dijo, pero Filis no le respondió. En el baño, Filis no quiso que Neera la cambiara. Recibió la ropa y cerró la puerta.

\section{LA PRENSA}

Los agentes de la Policía habían hablado con papá en una esquina, bastante próximos a la puerta de Emergencias. Ahí había estado Nico antes de que lo trasladaran a la sala de operaciones. Neera, la mayor de los hijos, los observaba a distancia, tratando de adivinar a través de los gestos de su padre, mientras abrazaba a
Filis que estaba sentada a su lado, en una mudez que luego se volvería una marca de su personalidad. Toda una vida era suficiente escuela para saber leer el lenguaje de los gestos. Papá fruncía el ceño impaciente y le aparecía esa arruga vieja y profunda que los asustaba de niños. Trataba de ser consistente en su aplomo y lo conseguía, pero estaba nervioso. Manejaba las manos de un modo más rígido que sereno, casi cortante. ¿Qué le pasa?, dijo en voz baja Neera, justo cuando su padre metió las manos en los bolsillos del pantalón. ¿Estaba nervioso o en realidad estaba reprimiendo la fuerza de un tractor, de una mole mecánica cuya única voluntad era la de aplastar?

Eso pensó Neera, aunque quién sabe si no era ella la que quería dar pelea, a pesar de sus esfuerzos de autocontrol y de la mirada de su padre que le exigía, como siempre, jvalor! Sacar fuerzas de una cantera que, en esas circunstancias, Neera no encontraba. No se llora en los momentos difíciles, carajo, decía papá. Podía repetirlo de memoria. De sus hermanos, ella era quien más sabía someter su corazón a la índole de un monasterio. Pero cuando apareció la prensa, no pudo o no supo. Sabía a lo que venían; ella misma había estado del otro lado miles de veces. No se dio cuenta cuándo ni con quién dejó a Filis. Solo saltó y les cerró el paso en el hall de la clínica, que ese momento parecía un hormiguero. Maldita ciudad en la que no pasa nada, se dijo. Camarógrafos de televisión, reporteros de radio con las grabadoras como armas de guerra, fotógrafos de crónica roja. 
Neera no se fue por los costados: Lo siento, compañeros, de aquí no pasan, dijo y se dio cuenta de que la voz la traicionaba. No los conocía, policiales nunca fue su área. Uno de los fotógrafos lanzó la luz de su flash hacia donde estaba Filis, todavía llena de sangre. Neera giró la cabeza siguiendo el recorrido del disparo y le dio un manotazo que casi hizo caer la cámara. Tuvo conciencia por unos segundos. Llenó entonces de aire su esternón y, en vez de cargarse de paciencia, los echó. Luego le dijo a Sergio: ¡La fregué! La explosión del World Trade Center seguiría en los periódicos paceños, pero ahora junto a la muerte de un niño en circunstancias extrañas. Un niño caído del edificio más alto de la ciudad. Un niño muerto, en ausencia de sus padres, solo en compañía de su hermana, también menor de edad. Se conjeturaba sobre un posible suicidio. "Niño se lanza de noveno piso», tituló uno. A pesar de que florecía el morbo en un charco de dudas, a Filis nadie le preguntó lo que pasó esa tarde: ni la policía, ni sus colegas, ni sus padres, ni sus hermanos. Nunca, ni en ese momento, ni años después. Al día siguiente, Neera compró los diarios de camino al cementerio, pero los dejó en el asiento de atrás del taxi. Esperaba que no hubiera tiempo para que los suyos los leyeran.

Estaba consciente de que la noche anterior los reporteros no se habían ido por ella sino porque Nico aún no estaba muerto. En ese momento no había noticia, o si la había, todavía no era un titular. El tiempo se volvía un caleidoscopio. Papá había llevado a sus hijos a una habitación pequeña y de luz blanca, rodeada de estantes cuyas cajas estaban perfectamente organizadas y nominadas: gasas, jeringas, Klosidol, Amoxicilina, Urbason, Ranitidina, Diazepan... Papá los había reunido, pero fue mamá la que dijo que iban a entrar al quirófano. Ni un quiebre: Klosidol, Amoxicilina, Diazepan... Era como si todos estuvieran apretando el estómago, aguantando la respiración debajo del agua, sabiendo que en algún momento tendrían que subir a la superficie y escuchar que el niño estaba muerto. Mamá les había explicado que las posibilidades eran remotas y que a pesar de que el procedimiento resultara, podría ocurrir

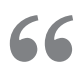
A pesar de que florecía el morbo en un charco de dudas, a Filis nadie le preguntó lo que pasó esa tarde: ni la policía, ni sus colegas, ni sus padres, ni sus hermanos. Nunca, ni en ese momento, ni años después.

que Nico quedara... ¿Vegetal?, completó Neera y se arrepintió de haberlo hecho frente a los rostros pétreos e innegociables de sus padres; sintió vergüenza de sí misma por haber pensado que ella no lo quería vegetal, que si era así, prefería que muriera.

Luego Nico murió y los hechos fueron más atropellados. La despedida, los trámites, la gente. Mañana habrá tiempo para llorar, Dios, oró papá. Él siempre había sido agnóstico o esotérico, o quién sabe qué, pero ¿católico? Era casi una cuestión de supervivencia, recordaría con los años mamá, como si papá empujara a presión los ladrillos de una pared, los contuviera con su cuerpo, con las manos, incluso con su cara, para que no se salieran de su sitio y de esa manera la construcción quedara en pie, aunque estuviera a punto de desplomarse. Papá, mamá, Neera, Adriano, Filis... Todos tenían un lugar y algo que hacer. Incluso Héctor, en la distancia, tenía un papel. Pobre Héctor, fue el único de los hermanos que no se despidió, pero también fue el único que pudo llorar. Lloró por todos hasta ahogarse de ira y de reproches. ¡Malditos! Tal vez un día papá lograría hacerle ver a Héctor que aquello no fue una afrenta y que en aquel sacrificio de no estar hubo una recompensa, aunque fuera diminuta, incluso perversa.

Mamá quería enterrar a Nico. No soporto verlo en un cajón, dijo, escueta y absoluta en su dolor. Nadie pudo convencerla de esperar. Cuánto habrían dado Adriano, Neera o la misma Filis por poder llorar ese día... Sobre todo Filis, que era llevada de un lugar a otro, acomodada en la esquina menos expuesta, tratada con esa suavidad que evitaba las preguntas y 
que, por lo tanto, la lastimaba tanto. Cuando miraba a su madre, Filis quería tragarse sus palabras: Mamá, Nico se «tiró» por la ventana. A papá se lo había dicho de otro modo: Nico se «cayó» de la ventana. Muchos años después, Filis le dijo así a su terapeuta: Un llanto seco nos estrangulaba y nos alejaba a unos de otros, con océanos de lágrimas no derramadas, con océanos de culpa. El único que había llorado verdaderamente era el pobre Héctor, huérfano, en la distancia, dijo papá. ¿Pobre por qué?, preguntó Filis en voz baja y su padre había fingido no escucharla. Neera, Héctor, Adriano, Filis. Era muy raro oír a papá nombrar a sus hijos, en orden, sin decir, al final: Nico.

\section{UNA FOTOGRAFÍA}

Eran las siete de la mañana, tal vez un poco más tarde. Adriano fue el último en salir del departamento. Todos estaban ya en el ascensor, cuan-

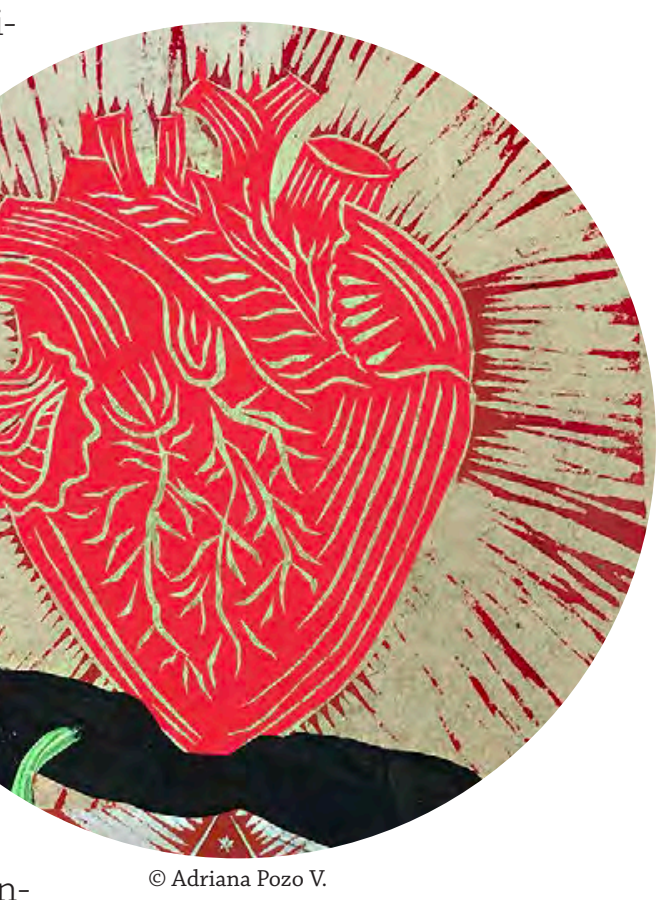
do en un impulso de último minuto decidió entrar de nuevo. Un momento, dijo, no tardo. Filis se miró fugazmente en el espejo. Papá le pasó la mano por el cabello, atado en una cola. Falta Héctor, dijo Filis. Mamá los observaba detrás de sus gafas oscuras, o quizás no miraba nada. Adriano volvió abrazado de su guitarra. Se recorrieron, nadie hizo preguntas, como si fuera normal llevar el instrumento al cementerio. Esa mañana, el cielo era una cavidad diáfana y dolorosamente azul en La Paz. Demasiada claridad, dijo mamá, recostando la cabeza en el vidrio. Mejor, pensó papá, apretándole la mano, en un gesto que mostraba su veterana intimidad. El camino se les hizo largo y papá comenzaba a conducir con impaciencia, pero los vehículos se sucedían unos a otros, lentamente, en la sonoridad de un vigoroso día laboral.

Filis sentía el mundo circular a mucha velocidad del otro lado de la ventana. El tráfico ya no era pausado, se había disuelto en 66 el desahogo de una larga avenida trabada de curvas, que la expulsaba desde su asiento hacia una náusea irregular e intensa. Le dolía el vientre. Apretó los ojos y se aferró al agarrador de la puerta. Sintió el sol en la cara, en un parque de diversiones cuyos juegos exhibían las coyunturas de un largo pasado. El sol en la cara y el viento trasegando el hedor de un río cargado con las aguas del centro de la ciudad; de la ciudad garita, de la ciudad mercado. Estos eran los parques que atracaban en La Paz, parques y circos atroces e irresistibles, recordaría en el futuro Filis. Nico corría feliz delante de ella para llegar a las sillas

\section{Un llanto seco nos estrangulaba y nos alejaba a unos de otros, con océanos de lágrimas no derramadas, con océanos de culpa.}


voladoras, indiferente a los columpios faltantes, a las cadenas oxidadas y a los ruidos de las maquinarias. Las sillas giraban sobre la muchedumbre, huyendo de su eje, del todo horizontales. Nico gritaba, con los brazos abiertos: ¡Filis, ¿no quieres volar?! Ella respondía desde la barda que no, que ni loca. El asco volvió a embestirla.

\section{6}

No podré recordarlo,

Alejandra, le había dicho

a su mujer. La imagen que

guardaba en la memoria

correspondía a una infancia

que ahora le parecía remota.

Héctor había llamado de madrugada desde Buenos Aires: ¿Qué hace la Nena despierta?, le había dicho. Era la primera vez que Filis hablaba, después de la muerte de Nico, tal vez el único diálogo que tuvo en esos días. No puedo dormir. Yo tampoco, dijo él. Héctor había llorado como una criatura en las faldas de su esposa. No podré recordarlo, Alejandra, le había dicho a su mujer. La imagen que guardaba en la memoria correspondía a una infancia que ahora le parecía remota. Al Nico adolescente no lo había conocido en verdad. No lo había visto transformarse, pegar el estirón. Chango, jodido. No lo había retratado. Héctor era fotógrafo. Tenía un taller de revelado en el baño del departamento, a la antigua, y cajas repletas de fotos; muchas de Nico y de Filis. Frente a la cámara, Nico creaba, hacía muecas y no tenía el menor miedo a inmortalizar el ridículo. Filis, en cambio, pasaba horas frente al espejo, practicando esa sonrisa escueta y un poco necesitada que repetía como si las produjera en serie. Cada vez que se reunían, Héctor actualizaba las fotos. Míralo aquí, Alejandra, sin dientes, totalmente k'asa ventana. Le gustaba jugar con él, fingir que sabían hablar en aymara, como papá. Kamisaraki, le decía en vez de «hola». Waliki, waliki, respondía Nico. Desde que él había comenzado a cambiar la voz, Héctor lo molestaba por teléfono: ¡Cómo anda el hombre de paja! Filis al principio no entendía, pero después comprendió que con "paja» se refería a la frecuencia con que su hermano paraba en el baño. Gringo k’ank'a, cochino. Nico se mataba de la risa.

No se habían visto hacía casi dos años. Héctor había postergado la vuelta a casa por sus viajes y porque sus padres lo habían visitado con cierta frecuencia. Por desidia, se castigaba él. Míralo aquí, tiene los ojos muy tristes. Siempre le había parecido que la alegría de Nico era un poco volátil. Voy a volverme loco, Alejandra, repítelo: ¡Nico fue feliz! ¿Por qué no me convences? Aquí también lo veo muy triste, yo también soy un hombre triste. ¿Quién puede saber si fue feliz, mierda, si nunca había nadie en esa casa, si todos estábamos tan ocupados? ¿Cómo puedo preguntárselo a Filis? Héctor se amordazaba con sus propias teorías. La voz de Filis lo conmovió, el abismo inconmensurable de su silencio. ¿Te cuento algo hasta que te dé sueño?, le propuso Filis. Ella sentía la ansiedad de su hermano, su afecto inhábil. Decidió contarle de las sillas voladoras. Héctor la escuchó. El sol en la cara y la explosión de un sollozo que él deglutía a la fuerza. Vamos a colgar, hermana. No le agradeció sino hasta muchos años después. Esa madrugada, se había consolado con la idea de un vuelo en vez de la caída. Solo así pudo tomar el avión a casa.

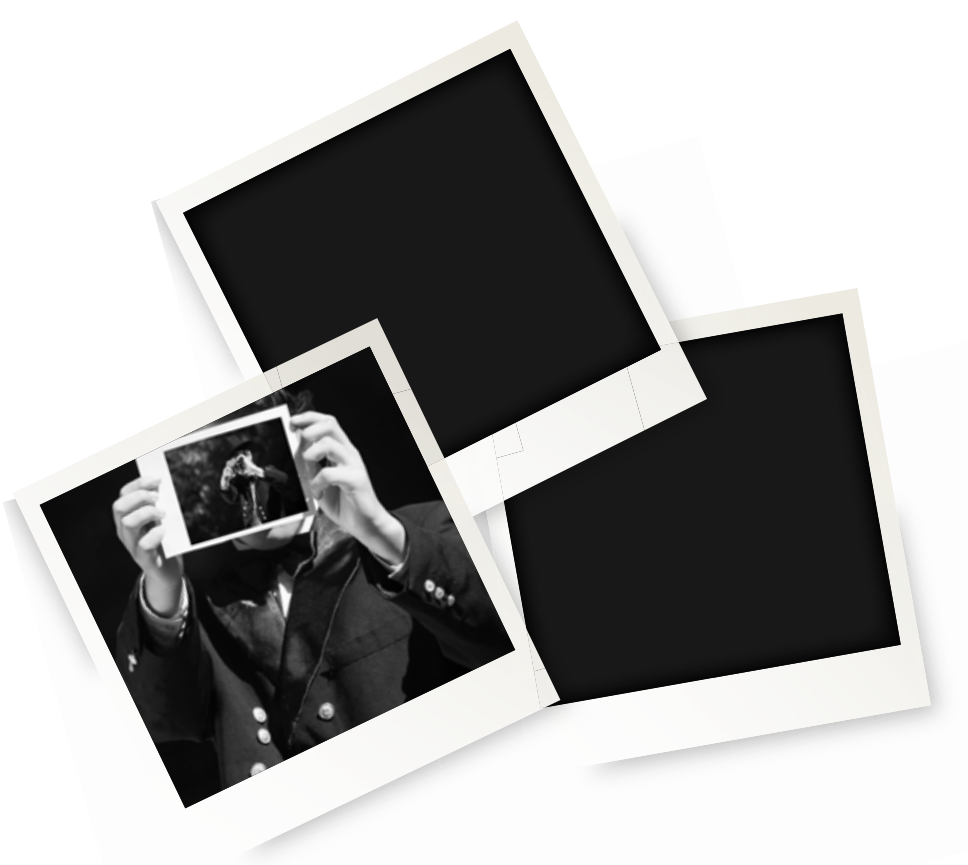

